\title{
How Moral Value Commitments Shape Responses to Political Civility and Incivility
}

Annemarie Walter (School of Politics and International Relations, University of Nottingham \& School of Governance, Law and Urban Development, Saxion University of Applied Sciences)

$\&$

Keena Lipsitz (Department of Political Science, Queens College and The Graduate Center, City University of New York) ${ }^{1}$

Manuscript accepted by American Politics Research, 3 March 2021

\begin{abstract}
Citizen exposure to political incivility is increasing. Studies have found heterogeneous responses to incivility, but we know little about what drives this variation. This study investigates whether emotional responses to both civility and incivility are driven by moral value commitments. Drawing on Moral Foundations Theory, we argue that incivility should pose more of a threat to people who embrace an individualizing system of moral regulation than a binding system. To test this, we conduct a $3 \times 3$ between-subjects survey-embedded vignette experiment with a representative sample of 1,789 U.S. respondents. The vignettes describe interactions between two candidates in a debate. The findings show that respondents clearly distinguish between civil, neutral, and uncivil debate and that these conditions yield distinct emotional responses. Moreover, we show "individualizers" have a stronger emotional response to incivility than "binders." Responses to civility, however, appear to be unaffected by moral value commitments.
\end{abstract}

\footnotetext{
${ }^{1}$ The author order is random and both authors contributed equally to the article.
} 
Political incivility is on the rise in the United States and the public has noticed. A

December 2018 poll found that 70 percent of Americans believe that the, "overall tone and level of civility" in politics has gotten worse since the November 2016 election. ${ }^{2}$ There is ample evidence to back up all of these observations. Scholars have noted the increase in incivility during electoral campaigns and in floor debates in Congress (Stryker 2011, 2013). The consequences of this rise in incivility are bleak. Research has found that when elites use uncivil political discourse, the public follows (Gervais 2016; 2014). It can also create a disdain for opposing views and reduce political trust (Mutz 2007). ${ }^{3}$ Thus, although there might be some contexts in which incivility is politically useful, most research suggests it degrades democracy.

These concerns about political incivility have compelled researchers to begin investigating how individuals respond to it and what might explain heterogeneity in their responses. Why does incivility anger some people while it leaves other unmoved? Many studies show that people vary in how they respond to negative or aversive stimuli in general so it is no surprise that there is considerable variation in responses to political incivility (Canli et al 2001; Soroka 2014). Several studies have found that male conservatives are more tolerant of it (Mutz 2015; Stryker and Danielson 2015; Fridkin and Kenney 2011). Others have found that strength of partisanship, political interest, and having less education increase this tolerance (Mutz 2015; Fridkin and Kenney 2011) but these effects are found less consistently. Media consumption also appears to be related to tolerating incivility, with those watching Fox News and The Daily Show having a particularly high tolerance (Styker and Danielson 2015). This study tries to uncover some of the deeper,

\footnotetext{
${ }^{2}$ NPR/PBS Marist poll. Available at http://maristpoll.marist.edu/npr-pbs-newshour-marist-pollnational-survey-results-analysis-civility/\#sthash.ytyDjHat.dpbs (accessed 10/30/20)

${ }^{3}$ But see Brooks and Geer 2007.
} 
psychological foundations that affect responses to incivility. In particular, we draw on Moral Foundations Theory (MFT) to determine how respondent preferences for certain systems of moral regulation shape emotional responses to incivility and civility.

Using a representative, online sample of 1789 respondents from the United States, this study uses a survey-embedded vignette experiment, which describes interactions between two Senate candidates during a debate, to assess how moral value commitments affect emotional responses to political civility and incivility. We manipulate the nature of the debate fragment (civil, neutral, uncivil) and find that those who have a stronger commitment to an individualizing system of moral regulation have a stronger emotional response to incivility than those who prefer a binding system. Responses to civility, however, appear to be unaffected by moral value commitments.

This study contributes to the field of political psychology in several ways. It is the first to link moral value commitments and responses to incivility. Second, unlike many studies, we explore variation in responses to both civility and incivility. ${ }^{4}$ This allows us to assess whether people recognize and appreciate civility or simply disapprove of incivility. Perhaps even more importantly, we include a neutral condition in our experiment which provides a crucial baseline for determining whether people are as sensitive to civility as they are to incivility. Studies that fail to include this crucial baseline (e.g. Mutz and Reeves 2005) cannot shed light on this question.

We begin by defining civility and incivility, as well as providing an overview of MFT and our hypotheses before turning to the analysis.

\footnotetext{
${ }^{4}$ For example, Brooks and Geer (2006) compare only neutral and uncivil ads. See for exception Sydnor (2015).
} 


\section{Defining Civility and Incivility}

There is no consensus on how to define civil or uncivil behavior. If one asks average Americans, political incivility includes everything from politicians calling each other names and using profanity to making empty promises and being "politically correct" (Muddiman and Kearney 2016). Scholars, however, tend to equate it more with simply being impolite and disrespectful. They have defined political incivility as, "instances where politicians humiliate their opponents and/or do not take them seriously" (Mölders et al. 2015; Laljee et al. 2009), "make claims that are inflammatory and superfluous" (Brooks and Geer 2007, 5), or use "gratuitous asides that suggest a lack of respect for and/or frustration with the opposition" (Mutz and Reeve 2005, 5). For the most part scholars focus on uncivil language not uncivil behavior, such as interrupting a debate opponent or rolling one's eyes. Yet, these forms of "discursive incivility" which are not utterances but behaviors that indicate disrespect or disdain are widely viewed as being uncivil by Americans (Stryker et al. 2016). We believe that the key element of all these incivility definitions is behaving in a manner that is disrespectful or demeaning towards others. This includes verbal utterances and non-verbal actions (e.g. eye-rolling).

Civility may be even more difficult to define than incivility. It is often likened to politeness, the purpose of which is to preserve social harmony, particularly among those who disagree. It accomplishes this by promoting "positive face" - the assurance that one is respected and valued-and "negative face" - the assurance that one will not be forced to do anything against one's wishes (Brown and Levinson 1989). In the realm of politics, civility and politeness, "sustain social harmony and allow people who disagree with one another to maintain ongoing relationships" (Strachan and Wolf 2012). The recognition that civility and politeness are essential to the smooth functioning of our political institutions has given rise to certain norms of behavior that shape how 
elected officials interact with one another. Thus, we define civility as communicating to others, either verbally or non-verbally, that they are respected, valued, and worthy of being heard.

\section{Systems of Moral Regulation}

Researchers have found that morality shapes political attitudes and behavior, including political ideology (Graham et al. 2012; Iyer et al. 2012; Haidt 2012; Lakoff 1996) ${ }^{5}$ and specific policy preferences (Koleva et. al 2012). Certain moral commitments can even affect a person's intention to vote (Johnson et al. 2014). Politicians understand this and use moral language strategically to elicit particular emotions from voters (Lipsitz 2016; Clifford and Jerit 2012). Thus, it is reasonable to expect moral commitments to affect responses to a range of political phenomena, including incivility.

Some might argue, however, that being civil is simply following rules or norms of polite behavior; it has little to do with morality or being a moral person. Yet, theorists have argued that a moral impulse lies behind norms of civility. Specifically, it is through civility that people communicate their respect for others as equals in a pluralistic society where people are bound to disagree. Chesire Calhoun (2000) argues that,

Civility norms regulate discussion ... by imposing speech constraints that prohibit the parties from expressing themselves in ways that might give a reasonable interlocutor cause to back out of the conversation altogether." (269).

\footnotetext{
${ }^{5}$ Recent work challenges the innateness of moral foundations and its relationship with political ideology (Smith et al. 2017; Ciuk 2018).
} 
Thus, civility requires obedience to social norms for a "moral aim" which is the, "communication of moral attitudes to fellow inhabitants of our moral world" (273). Because civility has this moral purpose we expect commitments to particular moral values and responses to both civility and incivility to be related.

Only one study has connected responses to morality and political incivility in any way. Mölders et al. (2015) argue that the way disrespectful communication in political debates affects voters' social judgments and voting decisions depends on voters' "moral identity," which is defined as the extent to which an individual desires having moral characteristics, such as being caring, compassionate, and friendly. ${ }^{6}$ While their study does find that "attachment to morality" explains some of the variation in responses to incivility, our approach digs deeper by exploring preferences for specific systems of moral regulation.

Haidt (2008) distinguishes two systems of moral regulation that regulate selfish impulses (Graham, Haidt, and Nosek 2009). The first centers on the individual and envisions a society in which people are best protected by giving individuals rights and erecting a legal system to protect them. In such a society, people are also taught to respect each other's rights. The moral foundations that undergird this "individualizing" system of moral regulation are care and fairness. A different system is one that says people are best restrained by giving them specific roles in enduring institutions that constrain their behavior. One such system might be the family. At one

\footnotetext{
${ }^{6}$ Walter and Redlawsk (2019) examine how moral value commitments shape the way citizens respond to politicians behaving in an immoral fashion, such as having an extramarital affair. Our study is focused specifically on how moral value commitments shape responses to incivility, which is a minor moral infraction if it is even a moral infraction at all (some would argue it is not). In addition, we examine the relationship between morality and civility.
} 
point in time another might have been the feudal system with its obligations between lord and serf. Such institutions bind people together into communities where each has an obligation to the other. The moral foundations associated with this 'binding' system of moral regulation are loyalty, respect for authority, and sanctity insofar as it emphasizes the relationship between believers and their god. This theory that argues that there are two overarching moral systems based on five moral foundations is called Moral Foundation Theory (MFT) (Graham et al. 2011)

We argue that incivility poses the greatest threat to the individualizing system of moral regulation. When people are bound in tightly-knit communities, incivility is unpleasant but it does not threaten the foundational institutions that hold them together. Someone who is uncivil simply needs to be reminded of the proper behavior for someone in his role. If someone in authority is uncivil to a subordinate that is simply the order of things; in hierarchical institutions, subordinates typically have no recourse. In contrast, an individualizing system of moral regulation treats everyone as equals with rights. We are supposed to approach each other assuming that everyone is worthy of respect and with the expectation that others will approach us assuming the same. Incivility is a fundamental violation of this assumption, because it communicates to others that they are not worthy of respect. Where civility communicates that you want to keep lines of communication with others, incivility shuts them down. This is why scholars from John Rawls to Dennis Thompson and Amy Gutmann have argued that civility is essential for a democracy to function. As Richard Boyd puts it,

Civility is tied up with a specific kind of political community, premised on the relationship of political equality that obtains between fellow citizens who rule and are ruled in turn in contrast to the patriarchal relationships between fathers and dependents, or the despotic rule of masters over slaves (Boyd 2006, 866). 
Incivility then is a greater threat to those who wish to live in a secular, tolerant society of equals. Thus, such "individualizers" should be much more sensitive to civil and uncivil behavior than “binders" (H1). ${ }^{7}$

\section{Affective Response to Incivility and Civility}

Research demonstrates that people react emotionally to political elites behaving in an uncivil fashion. While some have demonstrated that viewers experience emotional arousal through skin conductance tests (Mutz 2015), others show that people viewing political incivility report more anger and feelings of aversion (Gervais 2017). Little research examines emotional response to political civility but Mutz (2015) does find it is far less arousing than political incivility and that arousal partially depends on whether the civility involves televised close-ups (37). In a related area, researchers who study how people respond to people behaving in a morally upright fashion find they experience "other-praising emotions," such as admiration, gratitude, and elevation (Algoe and Haidt 2009). If elites going out of their way to be civil is a form of "moral excellence" than it is possible that political civility will evoke positive affect. Thus, we expect respondents to react emotionally to both incivility and civility, but given Mutz' (2015) findings, their response to civility is likely to be more muted (H2).

While there is good reason to believe that people will have an emotional response to both civility and incivility, a person's emotional response can also be indicative of a moral judgment. Over the last two decades, many moral psychologists have embraced a theory of "moral

\footnotetext{
${ }^{7}$ We would be remiss if we did not acknowledge that critiques of moral foundations theory exist (see Rai and Fiske 2011).
} 
intuitionism" which argues that moral judgment is not a product of rational thought and deliberation but rather linked to automatic and unconscious affective reactions (Haidt 2001). While there is some debate about where emotions occur in the process of arriving at a moral judgement (Huebner et al. 2009), there is mounting evidence that emotions are a crucial party of that process. Over the last few decades, researchers have employed a variety of methods to establish that emotions play an integral role in moral judgement. They have found that an individual's emotional response is largely "automatic," preceding moral judgement and profoundly shaping it (Bargh and Chartrand 1999). This has been established through the use of neuroimaging (Greene et al. 2001), case studies of individuals with brain damage (Anderson et al. 1999), and studies of facial expressions (Canon et al. 2010). Other scholars have demonstrated that artificially generating emotions in participants (e.g. through hypnosis or having subjects eat bitter foods), leads them to judge moral transgressions more harshly than people who have not had those emotions induced (Schnall et al. 2008;). Given this tight link between emotion and moral judgment, people who believe incivility is a moral violation should experience negative affect when exposed to it. Conversely, they should experience positive affect when exposed to civility if they believe it is a form of moral excellence. Our argument is that the people who are most likely to have these beliefs about civility and incivility are people with a strong commitment to individualizing foundations.

\section{Research Design and Operationalization of Concepts}

To examine voter responses to political civility and incivility and how this relationship is shaped by moral commitments, we embed a $3 \times 3$ between-subjects vignette experiment in survey. Using random assignment, we present each respondent with one of nine vignettes describing a fictional, but realistic-sounding exchange during a televised debate between an incumbent US Senator and his challenger. Across the vignettes, we vary the behavior of the challenger who we 
refer to as the "active candidate." ${ }^{\prime 8}$ We manipulated the nature of the active candidate's behavior (civil, neutral, uncivil) and the partisanship of both candidates (Republican, Democrat, nonpartisan). In the partisan conditions, the candidates were always from different parties. ${ }^{9}$

The partisan manipulation was included to ensure that responses to civil and uncivil behavior are not dependent on whether the candidate is a co-partisan. Yet, the manipulation had negligible effects (see Table A2.2 in the appendix), most likely because we mentioned the partisanship of the candidates only once in the vignettes. The fact that we did not find a strong partisan effect does not diminish the value of the experiment as this was not essential for testing our theory and it actually increases the statistical power of our subsequent analyses by allowing us to combine conditions. ${ }^{10}$

We varied the active candidate's behavior in the following manner. The civil treatment includes elements promoting "positive face" — the assurance that one is respected and valued—and "negative face" - the assurance that one will not be forced to do anything against one's wishes (Brown and Levinson 1989, 103). The positive face elements include Miller conveying that his

\footnotetext{
${ }^{8}$ Approximately half of the respondents said the treatments were "very realistic" or "realistic," one quarter said they were unrealistic, and the remainder fell in between (neither "realistic" nor "unrealistic"). These percentages were similar across the treatments.

${ }^{9}$ See the appendix for an overview of all conditions and stimuli.

${ }^{10}$ We pre-tested our civility treatments without partisan labels as we wanted to ensure that treatments were correctly perceived as civil, neutral and uncivil and that these perceptions were not driven by partisanship. We should have run an additional pre-test for our partisanship manipulation.
} 
opponent is admirable and deserving of respect. They also include an acknowledgement that both candidates share common goals (117). The main element of politeness promoting "negative face" includes a minimization of threat by showing deference (178). The uncivil treatment reverses these elements. Miller suggests his opponent does not deserve respect and demeans his contributions. He challenges the status of his opponent with his condescending and aggressive behavior, which includes an outright insult. He also suggests that his opponent is "not one of us" by claiming he does not share the same values. The neutral treatment includes none of this. We presented each respondent with a single vignette and obtained comparability by using statistical controls of subject characteristics to obtain unit homogeneity (King, Keohane and Verba, 1994). After exposure to a randomly assigned vignette, we ask respondents how they feel about Miller's behavior.

Analysis reveals that this behavioral manipulation was successful (see p. 5 in the appendix). Respondents found our civil vignette to be significantly more civil than the neutral vignette. On a scale of $0-100$, they rated them 76 and 68 , respectively $(\mathrm{p}<.05)$. Both the civil and neutral conditions were judged to be much more civil than the uncivil vignette, which was rated just 33 on the scale $(\mathrm{p}<.001)$.

The experimental study was collected online using Qualtrics from August 2-20 in 2017. A representative sample of 1789 respondents living in the United States was provided by Survey Sampling International (SSI), a market research firm. Although randomly assigned, the respondents were not allocated equally to one of the nine groups. The respondents had a 25 percent chance of being exposed to a neutral treatment, a 25 percent chance of being exposed to a civil treatment, and a 50 percent chance of being exposed to an uncivil treatment. Although 
different in size, the groups are highly similar to each other. ${ }^{11}$ We included more respondents in the uncivil condition to provide us with more statistical power should we pursue subset analysis with this group. ${ }^{12}$ The unequal group sizes does not affect our ability to engage in hypothesis testing or the size of our estimation effects.

Randomization checks confirm that after exclusion of these respondents, conditions were balanced on pre-treatment covariates with the exception of age (see p. 8 in the appendix). The respondents assigned to the civil condition tend to be on average four years younger than the respondents in the other cells. We correct for this imbalance by controlling for age in our statistical models.

\section{Operationalizing Reactions to Civility and Incivility}

As mentioned above, we measure the participant's response to the treatment by asking them how the behavior of the acting candidate described in the vignette makes them feel. Psychologists have long recognized that positive and negative affect are the two dominant emotional dimensions. They have also found that these dimensions are largely independent, meaning positivity and negativity are not the opposite of one another (Marcus 1988; Cappacio et al. 1997). As a consequence, we asked respondents to indicate the degree to which they were experiencing a range of positive and negative emotions, including anger, disgust, worry, enthusiasm, hope, and optimism, with the goal of creating a positive emotion scale and a negative emotion scale. Using factor analysis with a promax rotation, we confirmed that a two-dimensional

\footnotetext{
${ }^{11}$ See the appendix for details.

${ }^{12}$ For these reasons, we do not use survey weights in our analyses either.
} 
model of affect fits the data better than a single dimension. ${ }^{13}$ As a result of this analysis, we created a negative emotion scale by averaging anger, worry, and disgust responses and a positive emotion scale by averaging enthusiasm, hope, and enthusiasm responses. Both of these indices range from 0-100. The Cronbach's alpha for these scales are .88 and .93 , respectively.

We measure voters' moral values using the Moral Foundation Questionnaire (MFQ). MFQ measures the extent to which an individual endorses each of the five moral foundations developed by Graham et al. (2011). Participants rate how relevant each of 15 concerns are to them when making moral judgments (relevance items) and participants rate their agreements with 15statements that embody or negate each foundation (judgment items) (Koleva et al. 2012). MFQ is the most prominent method used to measure voters' moral foundations. ${ }^{14}$ The resulting measurement instrument covers a range of human moral concerns that has been demonstrated to be both reliable and valid in the U.S. adult population (Graham et al. 2011). For the analyses we make use of the 'two-factor model' that distinguishes between binding and individualizing foundations, which performs well. The Root Mean Square Error of Approximation (RMSEA) is 0.51, the Comparative Fit Index (CFI) 0.98 and the Standardized Root Mean Square Residual (SRMR) is 0.22 . We use the 15 -item moral relevance subset of the MFQ in our analyses as confirmatory analyses shows a strong format effect that generated heightened correlations between items of the same subsets (see p. 10 in appendix). The moral relevance items also perform better in terms of model fit (2-factor model) and have higher internal consistency than the judgment items.

\footnotetext{
${ }^{13}$ See p. 9 in the appendix for details.

${ }^{14}$ See http://www.moralfoundations.org/questionnaires for how to combine the scores on the questions to come to the subscales.
} 
For all of the analyses, however, we include robustness checks using the 30 item MFQ in the appendix.

We created the individualizing foundations index by averaging across the six indicators of commitment care and fairness. To create the binding foundations index, we averaged across the nine measures capturing the importance to one's life of loyalty, authority, and sanctity. The Cronbach alpha for the individualizing foundation index is .88. For the binding foundation index, it is .85. These two indices are correlated at $.67(\mathrm{p}<.001) .{ }^{15}$

We use ordinary least squares regression models for our analyses and include controls in the models to improve the efficiency of our estimates. In terms of socio-demographic characteristics, we control for respondent sex, age, race, education, and income. We also control for the respondent's partisanship. Sex is measured as a dichotomous variable ( $1=$ Male; $0=$ Female) as is race $(1=$ white; $0=$ non-white). Age is measured in years while education is measured with a variable ranging from 0 to 3, with 0 indicating that the respondent has a high school degree or less, a 2 indicating some college, a 3 indicating a college degree, and 4 indicating the respondent has a post-graduate education. Income ranges from 1 to 5. We determine an individual's partisan identification by asking them to indicate whether they are a Republican, a Democrat, an Independent, or something else. Independents who lean towards one of the two parties are reclassified as identifying with that party. ${ }^{16}$ Finally, because we did not force respondents to answer

\footnotetext{
${ }^{15}$ The correlation for the moral judgement individualizing and binding indices was $.42(\mathrm{p}<.001)$ while the correlation for indices that average all of the individualizing items (relevance plus judgement) and all of the binding items (relevance plus judgement) is .50 ( $\mathrm{p}<.001)$.

${ }^{16}$ See appendix for additional justifications of including controls in our analysis.
} 
each question before continuing, we have some missing values on the variables included in the analysis. Thus, the sample size for our regression analyses is 1517.

\section{Results}

<insert Figure 1 about here $>$ We begin by examining how voters respond emotionally to political civility and incivility. We expect respondents to experience more negative affect in the uncivil condition than the neutral and civil conditions. Conversely, they should experience more positive affect in the civil condition than in the neutral and uncivil conditions, but this reaction should be more muted than it is for incivility (H2). In addition, our manipulation check revealed that even though respondents found the civil treatment to be significantly more civil than the neutral treatment, they found the uncivil treatment to be much more uncivil than the neutral treatment. This is yet another reason why the emotional response to civility should be even more muted than the response to incivility. We see that $\mathrm{H} 2$ is largely confirmed. Voters exposed to the uncivil condition score an average of 49 on the negative emotion scale, in contrast to voters exposed to the civil and neutral condition that respectively score averages of 21 and 24 . While the difference between the uncivil treatment and the positive and neutral treatments is highly significant $(p<.001)$, the difference between the civil and neutral treatments is not. This is notable because respondents definitely perceived the civil treatment to be more civil than the neutral treatment. It just fails to elicit a commensurate reduction in negativity. The mean positive emotion score in the civil treatment is 56 and 47 in the neutral condition $(\mathrm{p}<.001)$. It is significantly lower in the uncivil condition at 26. Thus, while incivility appears to suppress positive affect as much as it increases negative affect, civility appears to boost positive affect without affecting negative affect much.

<insert Table 1 about here> 
In Table 1, we estimated four ordinary least squares models to examine how the civil, neutral, and uncivil treatments affected reported negative and positive emotion. The first two models do not include an interaction between the moral foundations measures and treatment groups while the second two models do. The models including the interaction terms explain significantly more of the variance in the dependent variable than the first two models $(.30$ vs. 28 for the negative emotion scale and .29 vs. .28 for positive emotion scale). If H1 is supported, then the interaction term for the civil condition and commitment to individualizing foundations should be negative and significant in the model explaining negative affect and positive and significant in the model explaining positive affect. This would suggest that individualizers have a stronger emotional reaction to civility than non-individualizers. The reverse should be true for the interaction term between the uncivil condition and individualizing foundations suggesting that individualizers have a stronger emotional reaction to incivility as well. Finally, H1 suggests that the coefficient for the interaction between the treatments and measure of commitment to binding foundations should be small and insignificant.

Table 1 confirms much of H1. First, the coefficients for the interactions between the treatment groups and the measures of binding foundations are small and insignificant as predicted. Both binders and non-binders respond in a similar way to civility and incivility. Individualizers also have a significantly stronger emotional reaction to incivility both in terms of positive and negative affect than non-individualizers as predicted. The 9.65 coefficient in the model explaining negative affect is positive, large, and highly significant, while the -7.26 coefficient in the model explaining positive affect is negative, large, and highly significant. In Model 3 of Table 1 however, the 4.71 coefficient for the interaction term between the civil condition and individualizing foundations is surprisingly positive and statistically significant when we expected it to be negative, however. In Model 4 which explains positive affect, the coefficient is small and statistically insignificant. Thus, 
our analysis does confirm all of $\mathrm{H} 1$. To help make sense of these findings, we have graphed the predicted margins in Figure 2.

$$
<\text { insert Figure } 2 \text { about here }>
$$

The graphs in Figure 2 show how a commitment to individualizing foundations moderates respondents' emotional reaction in the three treatment groups. In the left graph, individualizers report significantly more negative affect than respondents in the neutral and civil conditions, but importantly with respect to $\mathrm{H} 1$, they report significantly more negative affect in the uncivil condition than non-individualizers. As one moves from the $10^{\text {th }}$ to the $90^{\text {th }}$ percentile $(3.33$ to 5.83 ), the predicted negative affect score climbs from 46 to $52(\mathrm{p}<.05)$. In the right graph, we see that individualizers report significantly more positive affect than non-individualizers in the incivility condition. Reported positive affect declines from 34 to $14(\mathrm{p}<.001)$ as one moves from the $10^{\text {th }}$ to the $90^{\text {th }}$ percentile in individualizing foundations. In both graphs, we see a pattern of divergence across the three conditions as respondents report a higher moral value commitment. What is unexpected is that this commitment does not make any difference in how respondents react to civility. On the left, it does appear that individualizers experience slightly less negative emotion in the civil condition than non-individualizers but the effect is not statistically significant. We discuss possible explanations for this finding below.

\section{Conclusion}

At a time when political incivility is on the rise, it is more important than ever to understand how it affects citizens. Using a between-subjects embedded survey experiment, we show that voters' emotional responses to incivility are driven by their moral value commitments. Specifically, we show that citizens who subscribe to an individualizing system of moral regulation 
have a stronger emotional response to incivility than those who subscribe to a binding system of moral regulation. We believe this is because individualizers view civility as the glue that holds people together in a pluralistic society where citizens are bound to disagree but must continue to work together. For them, incivility is a significant threat because it communicates disrespect and makes cooperation difficult, if not impossible. For binders, incivility is unpleasant but it is not a threat in the same way because relationships created by traditional, mostly hierarchical societal institutions hold people together and govern how they behave. People will continue to work together because their societal roles demand it. An uncivil servant is still a servant. Individualizers reject such roles, which leaves civility as the key binding force in society.

Although individualizers have a stronger response to incivility than non-individualizers, there was no difference in how the two responded to civility. One explanation for this might be that there are floor and ceiling effects at play. Perhaps people simply find it difficult to experience really low negative or really high positive affect when confronted with a political debate or just about anything related to politics these days. Another possibility is that people respond more strongly to moral violations than examples of moral excellence. The latter is "nice" but moral transgression is what must be policed to preserve social order. Future research might investigate these possibilities.

Despite the fact that moral foundations do not moderate responses to civility, our empirical results demonstrate that voters not only recognize and appreciate when politicians behave civilly to one another, but that they also clearly distinguish civil from neutral debate and respond to them differently. By comparing incivility solely to a neutral stimulus (i.e. disregarding civility as a condition) or by pretending that a neutral stimulus is the same as a civil stimulus, one implicitly assumes that civility does not exist, that it does not constitute distinct behavior, and that it does not 
generate distinct emotional responses. In addition, examining the effects of incivility relative to a civil baseline rather than one that is neutral will lead one to overstate the effects of incivility. Thus, we encourage future researchers to move beyond the study of incivility and to examine the full phenomenon.

Of course, the current study is not without its shortcomings. First of all, the experiment does not vary levels of civility and incivility even though we know that there is considerable variation in both kinds of behavior. Future research needs to pay more attention to this variation and how emotional responses correlate with it. Second, like other vignette studies, this one traded external validity for internal validity. Irrespective of how realistic the vignettes might have sounded to respondents, it is still a written description. Third, this study failed to find a partisan effect that is found in some other studies on incivility. Although all vignettes were pre-tested for their realism, the extent to which they evoked emotional responses, and were correctly perceived as civil, neutral or uncivil by respondents, we did not pre-test whether the partisan prompts were strong enough. We hope others learn from our mistake.

Finally, this study was conducted at a time that seems to be increasingly characterized by political incivility. Although this study took place nine months after the rancorous 2016 United States presidential election, it is still possible that participants' responses were affected by the current political climate. Nevertheless, we hope this study can be replicated in a less politically polarized time or place to validate our findings and shed more light on how variation in political context affects the way voters respond to the behavior of politicians. 
Table 1: How Commitment to Individualizing Foundations Moderates Emotional Responses to Civil, Neutral, and Uncivil Treatments

\begin{tabular}{|c|c|c|c|c|}
\hline VARIABLES & $\begin{array}{l}\text { Negative } \\
\text { Emotion } \\
\text { (Model 1) }\end{array}$ & $\begin{array}{c}\text { Positive } \\
\text { Emotion } \\
\text { (Model 2) }\end{array}$ & $\begin{array}{l}\text { Negative } \\
\text { Emotion } \\
\text { (Model 3) }\end{array}$ & $\begin{array}{c}\text { Positive } \\
\text { Emotion } \\
\text { (Model 4) }\end{array}$ \\
\hline Civil & $\begin{array}{l}-3.52 * \\
(1.77)\end{array}$ & $\begin{array}{c}9.08^{* * *} \\
(1.84)\end{array}$ & $\begin{array}{c}-20.21 * \\
(8.34)\end{array}$ & $\begin{array}{c}8.73 \\
(8.74)\end{array}$ \\
\hline Uncivil & $\begin{array}{c}27.50 * * * \\
(1.53)\end{array}$ & $\begin{array}{c}-24.13^{* * *} \\
(1.60)\end{array}$ & $\begin{array}{c}-15.79 * \\
(7.55)\end{array}$ & $\begin{array}{c}0.71 \\
(7.91)\end{array}$ \\
\hline Individualizing foundations & $\begin{array}{l}-1.09 \\
(0.85)\end{array}$ & $\begin{array}{c}-4.14 * * * \\
(0.88)\end{array}$ & $\begin{array}{c}-7.03 * * * \\
(1.66)\end{array}$ & $\begin{array}{l}-0.68 \\
(1.74)\end{array}$ \\
\hline Binding foundations & $\begin{array}{c}2.89 * * \\
(0.93)\end{array}$ & $\begin{array}{c}5.11 * * * \\
(0.97)\end{array}$ & $\begin{array}{l}3.71 * \\
(1.76)\end{array}$ & $\begin{array}{l}3.94 * \\
(1.84)\end{array}$ \\
\hline Civil*Individualizing foundations & -- & -- & $\begin{array}{l}4.71 * \\
(2.28)\end{array}$ & $\begin{array}{c}0.35 \\
(2.39)\end{array}$ \\
\hline Uncivil*Individualizing foundations & -- & -- & $\begin{array}{c}9.65^{* * *} \\
(2.01)\end{array}$ & $\begin{array}{c}-7.26^{* * * *} \\
(2.10)\end{array}$ \\
\hline Civil*Binding foundations & -- & -- & $\begin{array}{l}-1.18 \\
(2.46)\end{array}$ & $\begin{array}{l}-0.31 \\
(2.58)\end{array}$ \\
\hline Uncivil*Binding foundations & -- & -- & $\begin{array}{l}-0.33 \\
(2.15)\end{array}$ & $\begin{array}{c}2.05 \\
(2.25)\end{array}$ \\
\hline Constant & $\begin{array}{c}21.10^{* * *} \\
(4.12)\end{array}$ & $\begin{array}{c}46.15^{* * *} \\
(4.29)\end{array}$ & $\begin{array}{c}44.73^{* * *} \\
(6.31)\end{array}$ & $\begin{array}{c}35.34 * * * \\
(6.62)\end{array}$ \\
\hline Observations & 1,517 & 1,517 & 1,517 & 1,517 \\
\hline Adjusted R-squared & 0.28 & 0.28 & 0.30 & 0.29 \\
\hline
\end{tabular}


Figure 1: Emotional Response to Civil, Neutral, and Uncivil Treatments
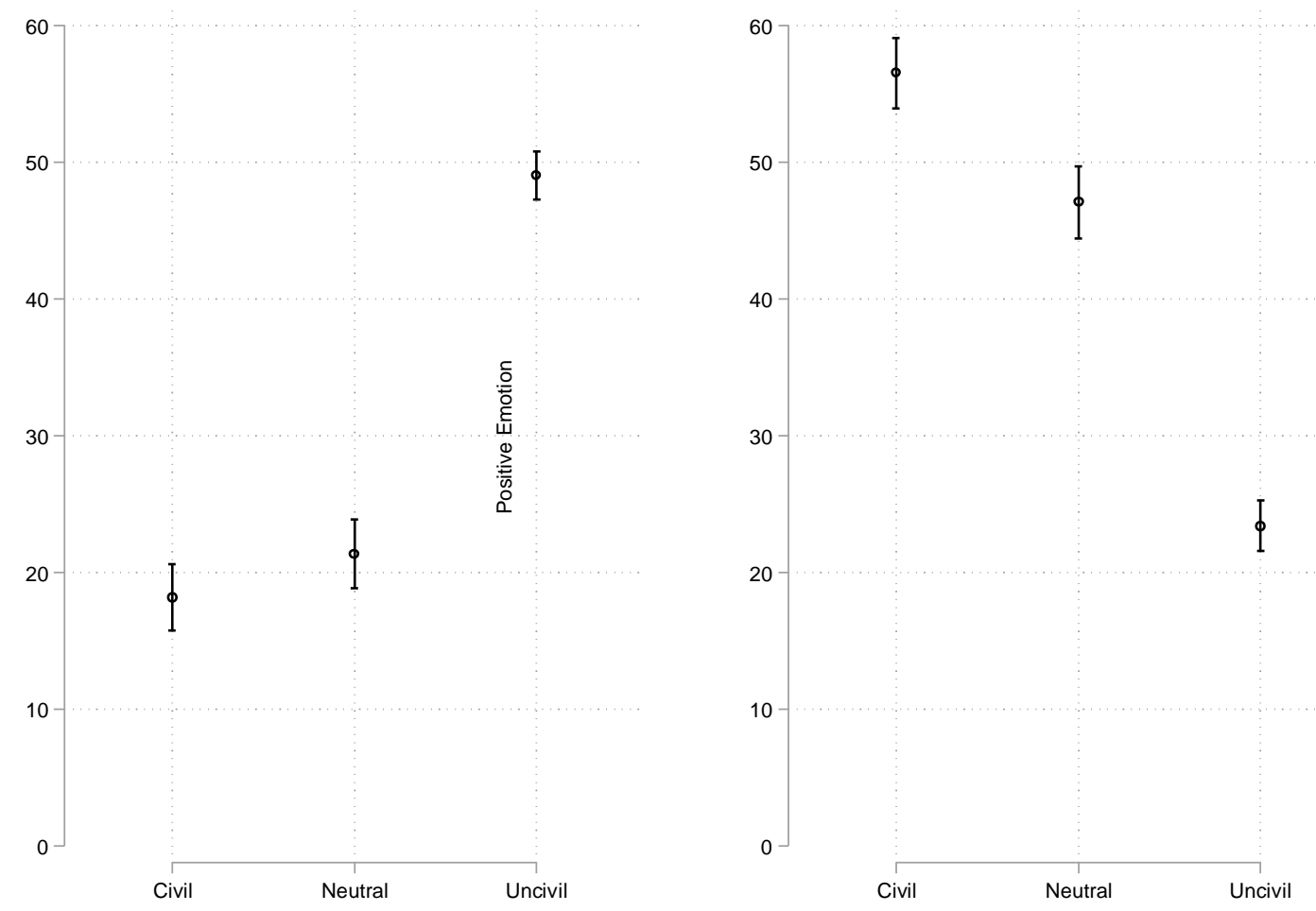

$N=1517$. Adjusted marginal means calculated after estimating ANOV A model. Ninety-five percent confidence intervals shown. There were 388 respondents in the civil condition, 370 in the neutral condition, and 759 in the uncivil condition. 
Figure 2: How Commitment to Individualizing Foundations Moderates Emotional Responses to Uncivil, Civil, and Neutral Treatments
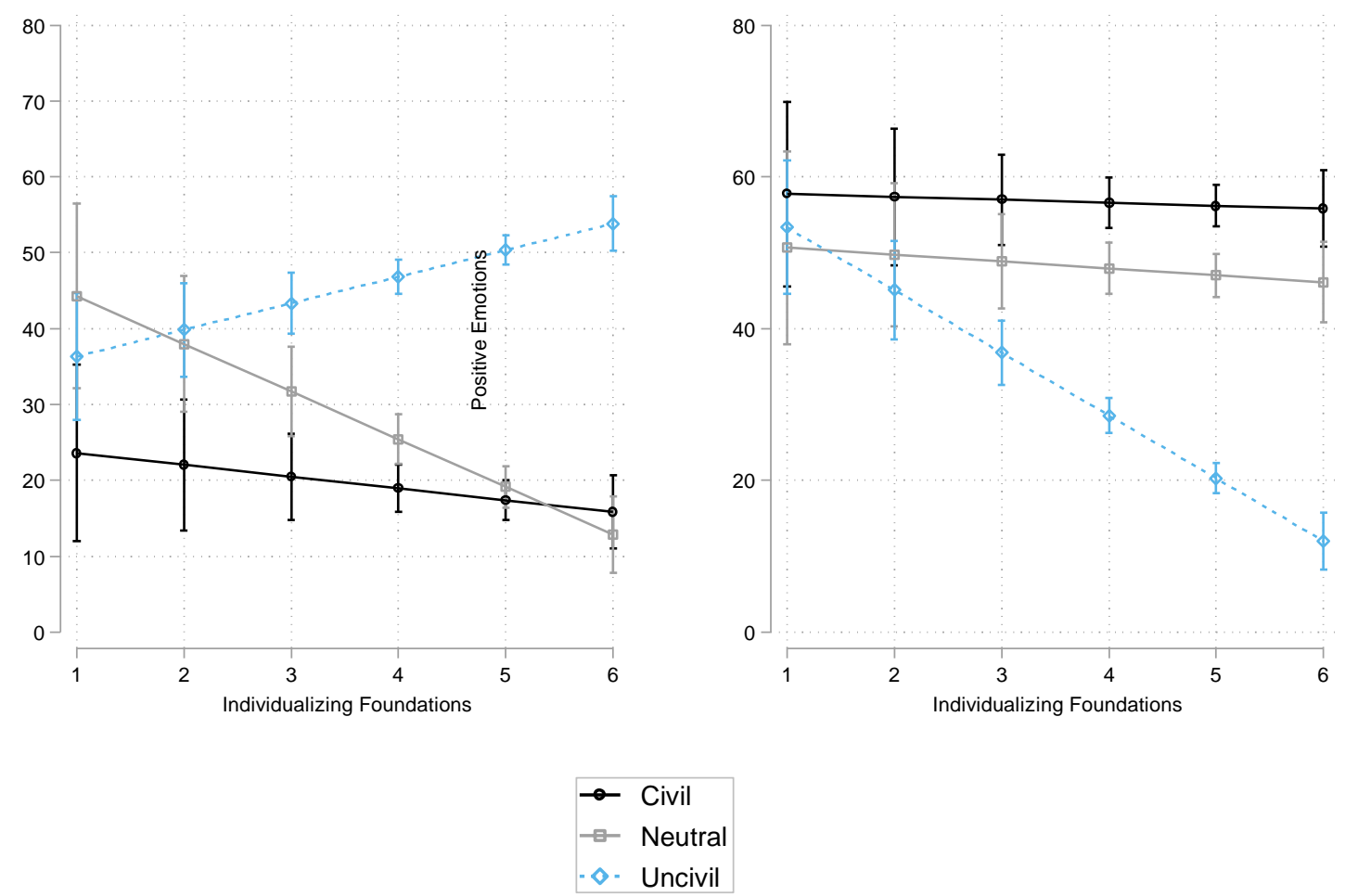

$N=1517$. Predicted margins with ninety-five percent confidence intervals shown.

\section{References:}

Anderson, S. W.,Bechara, A., Damasio, H., Tranel, D. and Damasio, A.R. (1999). Nature

Neuroscience, 2, 1032-1037.

Bargh, J. A., \& Chartrand, T. L. (1999). The unbearable automaticity of being. American Psychologist, 54(7), 462-479.

Brooks, D. J. and Geer, J. G. (2007). Beyond Negativity: The Effects of Incivility on the Electorate, American Journal of Political Science, 51 (1): 1-16. 
Canli, T, Zhao, Z., Desmond J. E., Kang, E., Gross,J. and Gabrieli, J. E. (2001). An fMRI study of personality influences on brain reactivity to emotional stimuli, Behavioral neuroscience, 115 (1): $33-42$.

Cannon, P. R., Schnall, S., \& White, M. (2011). Transgressions and expressions: Affective facial muscle activity predicts moral judgments. Social psychological and personality science, 2(3), $325-331$.

Ciuk, D. J. (2018). Assessing the contextual stability of moral foundations: Evidence from a survey experiment, Research \& Politics, https://doi.org/10.1177/2053168018781748

Clifford, S and Jerrit, J. (2013) How words do the work of politics: Moral foundations theory and the debate over stem cell research. Journal of Politics, 75 (3), 659-671.

Fridkin, K. L. and Kenney, P. J. (2011) Variability in Citizens' Reactions to Different Types of Negative Campaigns, American Journal of Political Science, 55 (2): 307-325.

Gervais, B. T. (2016). More than Mimicry: The Role of Anger in Uncivil Reactions to Elite Political Incivility, International Journal for Public Opinion Research, doi: 10.1093/ijpor/edw010

Gervais, B. T. (2014). Following the News? Reception of Uncivil Partisan Media and the Use of Incivility in Political Expression, Political Communication, 31: 564-583.

Graham, J., Nosek, B. A., Haidt, J., Iyer, R., Koleva, S. and Ditto, P. H. (2011). Mapping the Moral Domain, Journal of Personality and Social Psychology, 101(2): 366-385.

Haidt, J. \& Hersh, M. A. (2001) Sexual Morality: The Cultures and Emotions of Conservatives and Liberals. Journal of Applied Psychology, 31 (1), 191-221

Haidt, J. (2008). Morality. Perspectives on Psychological Science, 3, 65-72.

Iyer, R., Koleva, S., Graham, J., Ditto, P. and Haidt, J. (2012) Understanding Libertarian Morality: The Psychological Dispositions of Self-Identified Libertarians, PLos One, 7 (8): e42366 
Johnson, K. M., Iyer, R., Wojcik, S. P., Vaisey, S., Miles, A., Chu, V. and Graham, J. (2014).

Ideology-specific patterns of moral indifference predict intentions not to vote, Analyses of Social Issues and Public Policy, 14 (1): 61-77.

King, G., Keohane, R. O., and Verba, S. (1994). Designing social inquiry: Scientific inference in qualitative research. Princeton University Press.

Koleva, S. P., Graham, J., Ravi, I., Ditto, P. H. and Jonathan Haidt (2012). Tracing the threads:

How five moral concerns (especially Purity) help explain culture war attitudes, Journal of

Research in Personality, 46 (2): 184-194.

Lipsitz, Keena (2018). "Playing with Emotions: The Effect of Moral Appeals in Elite Rhetoric." Political Behavior 40(1): 57-78.

Mölders, C., van Quabeke, N., Paladino, M. P. (2015). Consequences of Politicians’ Disrespectful Communication Depend on Social Judgment Dimensions and Voters' Moral Identity, Political Psychology, already published online

Muddiman, A. and Kearney, M.(2016) Incivility to Individuals: An Inductive Approach to Political Incivility, Paper presented at APSA Political Communication Pre Conference, 27 August 2016, pp. 30

Mutz, D. (2007) Effects of “In-Your-Face” Television Discourse on Perceptions of a Legitimate Opposition, American Political Science Review, 101 (4): 621-635.

Mutz, D. C. and Reeves, B. (2005). The New Video malaise: Effects of Televised Political Incivility on Political Trust, American Political Science Review, 99 (1): 1-15.

Rai, T.S., Fiske, A.P. (2011). Moral psychology is relationship regulation: moral motives for unity, hierarchy, equality, and proportionality. Psychol. Rev. 118, 57-75.

Schnall, S., Haidt, J., Clore, G. L., \& Jordan, A. H. (2008). Disgust as embodied moral judgment. Personality \& Social Psychology Bulletin, 34(8), 1096-1109. 
Smith, K. B., Alford, J. R., Hibbing, J. R., Martin, N. G. \& Hatemi, P. K. (2017). Intuitive Ethics and Political Orientations: Testing Moral Foundations as a Theory of Political Ideology. American Journal of Political Science, 61, 2, 424-437.

Soroka, S. N. (2014). Negativity in Democratic Politics: Causes and Consequences. Cambridge: Cambridge University Press

Sydnor, E. (2015). Fighting Words and Fiery Tone: The Interaction of Political Incivility and Psychological Conflict Orientation, Dissertation, University of Virginia

Stryker, R., Conway, B. A. \& J. T.r Danielson (2016). What is Political Incivility?, Communication Monographs, 83 (4): 535-556. 